\title{
Comparison of generation 3 polyamidoamine dendrimer and generation 4 polypropylenimine dendrimer on drug loading, complex structure, release behavior, and cytotoxicity
}

\author{
This article was published in the following Dove Press journal: \\ International Journal of Nanomedicine \\ 15 December 2011 \\ Number of times this article has been viewed
}

\author{
Naimin Shao' \\ Yunzhang Su' \\ Jingjing $\mathrm{Hu}^{2}$ \\ Jiahai Zhang ${ }^{3}$ \\ Hongfeng Zhang' \\ Yiyun Cheng ${ }^{1,4}$
}

'School of Life Sciences, East China Normal University, Shanghai, ${ }^{2} \mathrm{CAS}$

Key Laboratory of Soft Matter

Chemistry, Department of Chemistry,

University of Science and Technology

of China, Hefei, ${ }^{3}$ School of Life

Sciences, University of Science

and Technology of China, Hefei,

${ }^{4}$ Shanghai Key Laboratory of Magnetic

Resonance, Department of Physics,

East China Normal University,

Shanghai, China

\begin{abstract}
Background: Polyamidoamine (PAMAM) and polypropylenimine (PPI) dendrimers are the commercially available and most widely used dendrimers in pharmaceutical sciences and biomedical engineering. In the present study, the loading and release behaviors of generation 3 PAMAM and generation 4 PPI dendrimers with the same amount of surface amine groups (32 per dendrimer) were compared using phenylbutazone as a model drug.

Methods: The dendrimer-phenylbutazone complexes were characterized by ${ }^{1} \mathrm{H}$ nuclear magnetic resonance and nuclear Overhauser effect techniques, and the cytotoxicity of each dendrimer was evaluated.

Results: Aqueous solubility results suggest that the generation 3 PAMAM dendrimer has a much higher loading ability towards phenylbutazone in comparison with the generation 4 PPI dendrimer at high phenylbutazone-dendrimer feeding ratios. Drug release was much slower from the generation 3 PAMAM matrix than from the generation 4 PPI dendrimer. In addition, the generation 3 PAMAM dendrimer is at least 50-fold less toxic than generation 4 PPI dendrimer on MCF-7 and A549 cell lines.

Conclusion: Although the nuclear Overhauser effect nuclear magnetic resonance results reveal that the generation 4 PPI dendrimer with a more hydrophobic interior encapsulates more phenylbutazone, the PPI dendrimer-phenylbutazone inclusion is not stable in aqueous solution, which poses a great challenge during drug development.
\end{abstract}

Keywords: dendrimer, polyamidoamine, polypropylenimine, drug delivery, cytotoxicity

\section{Introduction}

Dendrimers are synthetic macromolecules with hyperbranched structures, well defined ellipsoidal or globular shapes, and precise molecular weights. ${ }^{1,2}$ In comparison with traditional linear polymers, dendrimers have shown the following advantages when they are used as drug carriers: high drug loading ability endowed by the large numbers of surface functionalities and interior cavities; ${ }^{3,4}$ high bioavailability of drugs covalently or noncovalently attached to dendrimers because of the high penetration ability of dendrimers across cell membranes and biological barriers; ${ }^{5}$ reproducible pharmacodynamic and pharmacokinetic behavior of dendrimer-based drug formulations due to their well defined structure and extremely low polydispersity; ${ }^{6}$ multifunctional scaffolds for both targeted diagnosis and therapy given that the dendrimer can be easily functionalized with various bioactive moieties; ${ }^{7-9}$ and stable monomolecular micelles in physiological conditions which avoid the disassembly of amphiphilic polymeric
Correspondence: Yiyun Cheng

School of Life Sciences, East China

Normal University, Shanghai, China

Tel +862154342935

Fax +862154342935

Email yycheng@mail.ustc.edu.cn

Hongfeng Zhang

School of Life Sciences, East China

Normal University, Shanghai, China

Tel +862162233549

Fax +86 2l 62233754

Email hfzhang@bio.ecnu.edu.cn 
micelles below their critical micelle concentrations. ${ }^{1}$ Integrating these versatile features into a single molecule, dendrimers have become competitive candidates as drug carriers in the pharmaceutical industry. ${ }^{10}$

Up to now, the polyamidoamine (PAMAM) dendrimer reported by Tomalia in 1985 and polypropylenimine (PPI) dendrimer synthesized by Meijer et al in 1993 are the most investigated dendrimers in the fields of drug delivery (Scheme 1). ${ }^{11,12}$ These two commercially available dendrimers were synthesized by a divergent strategy, in which the construction of dendrimer takes place in a stepwise manner by coupling repeated units to a central core, providing a series of radically concentric layers called "generations". ${ }^{1}$ Structurally, PAMAM dendrimer was synthesized by Michael addition of amine with acrylic acid methyl ester, followed by the aminolysis of the resulting ester by ethylene diamine to create new reaction sites for further Michael additions. ${ }^{11}$ Similarly, PPI dendrimer was initiated by the Michael addition of amine with acrylonitrile and followed by the reduction of nitrile groups to yield primary amine groups which provides new branching points. ${ }^{12}$

PAMAM and PPI dendrimers have excellent aqueous solubility which ensures stable aqueous dispersion of PAMAMbased and PPI-based drug formulations. ${ }^{1}$ Full-generation PAMAM and PPI dendrimers are usually terminated with primary amine groups ( $\mathrm{pKa}$ about 10.0), and the cationic surface of PAMAM and PPI can bind a large amount of negatively charged drugs through electrostatic interactions. ${ }^{13}$

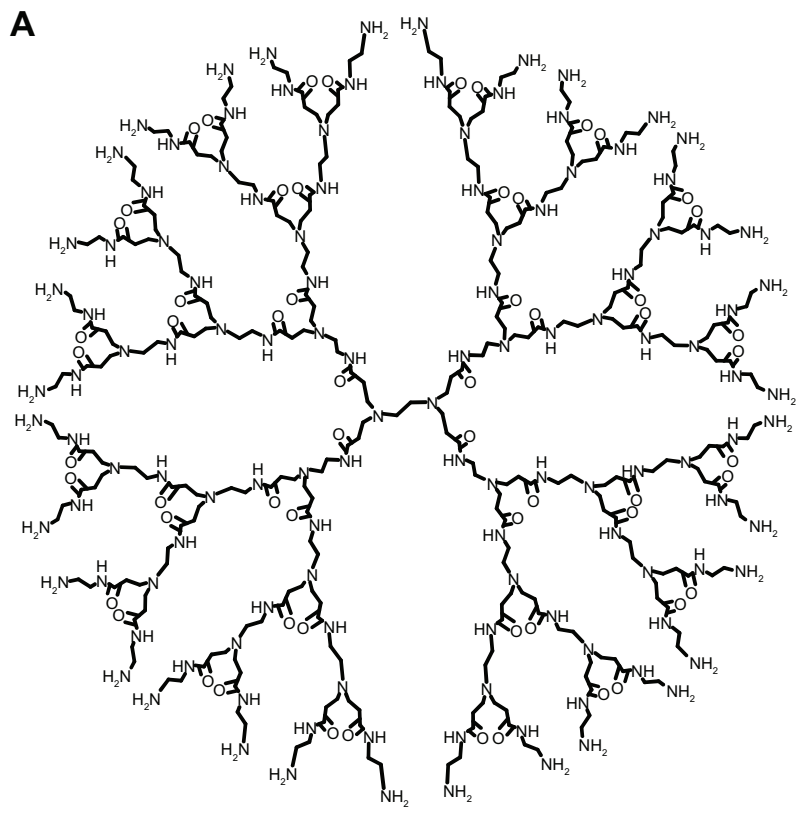

Low-generation PAMAM and PPI dendrimers have an open structure with an ellipsoidal shape and inner pockets which can be used to encapsulate hydrophobic drugs. ${ }^{14,15}$ The predominant difference in the structure of PAMAM and PPI is their interior pockets, ie, PAMAM has relatively polar pockets consisting of alkyl chain, tertiary amine, and amido groups, while PPI possesses nonpolar pockets consisting of alkyl chain and tertiary amine groups. ${ }^{16}$ In addition, the length of branching units for PAMAM (seven bonds) is different from that of PPI dendrimer (four bonds), indicating that the size of PAMAM dendrimer is much larger than that of PPI dendrimer with an equivalent number of surface amine groups. These structural differences may have interesting physicochemical implications for the host behavior of PAMAM and PPI dendrimers. The binding constants of dendrimer and phenol blue are an order of magnitude larger for PPI versus PAMAM with the same amount of surface groups, indicating fewer polar pockets of PPI dendrimer. ${ }^{16}$ Dendrimer with a PPI core and a PAMAM shell encapsulates hydrophobic pyrene molecules in the PPI layers rather than in the PAMAM layers. ${ }^{17}$ Also, PAMAM and PPI dendrimers exhibited distinct behaviors in their ionic interactions with negatively charged guests, such as vitamins $\mathrm{C}, \mathrm{B}_{3}$, and $\mathrm{B}_{6}{ }^{18}$ In a separate study, isobutyramide-terminated PPI dendrimer was found to be more hydrophobic than PAMAM dendrimer with an equivalent number of isobutyramide groups, ${ }^{19}$ probably due to the higher density of surface groups and the more hydrophobic interior of PPI dendrimer.

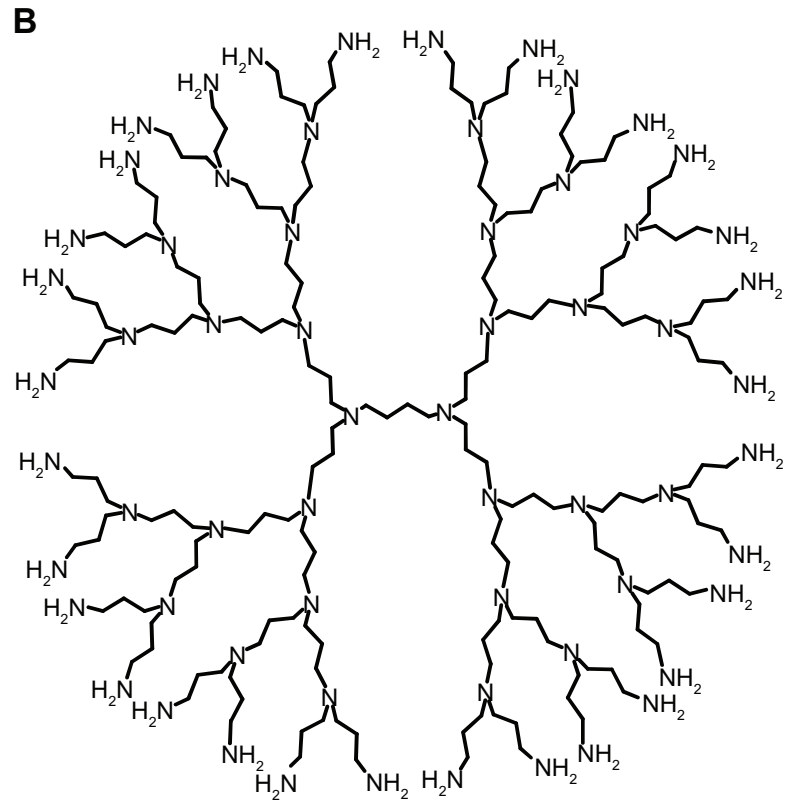

Scheme I Molecular structures of PAMAM (A) and PPI (B) dendrimers. Abbreviations: PAMAM, polyamidoamine; PPI, polypropylenimine. 
In our previous studies, we have demonstrated that PAMAM dendrimers are able to solubilize different families of hydrophobic drugs. ${ }^{20}$ In comparison with interior encapsulation, surface ionic interaction was found to be the major factor on the solubilization behavior of PAMAM dendrimer. ${ }^{3,13}$ The host behaviors of PAMAM dendrimer towards a list of drugs were analyzed by ${ }^{1} \mathrm{H}$ nuclear magnetic resonance (NMR) titrations, ${ }^{21}$ nuclear Overhauser effect spectroscopy (NOESY), ${ }^{3}$ and pulsed-field gradient NMR. ${ }^{22}$ The release of drugs from the PAMAM dendritic matrix depends on dendrimer generation and surface functionality, ionic strength, $\mathrm{pH}$ conditions, and the solvent. ${ }^{21}$ PAMAM dendrimer exhibits low biocompatibility in A549 and MCF-7 cell lines, and the removal of surface charges on PAMAM dendrimer by acetylation can completely neutralize the cytotoxic activity of dendrimer on these cells. ${ }^{23}$ All these studies suggest that the surface amine groups on PAMAM dendrimers are of central importance in the binding, release, and biocompatibility of this polymeric nanocarrier. Furthermore, PPI dendrimers were also able to enhance the solubility of hydrophobic drugs, increase their stability, and prolong their delivery in different routes. ${ }^{24}$ However, systematic comparisons on the loading and release behaviors of PAMAM and PPI dendrimer as well as their complex structures with drugs are limited.

In this present study, we focused on comparing PPI and PAMAM dendrimers in five aspects, ie, drug loading efficiency, host-guest chemistry, complex stability, in vitro drug release behavior, and cytotoxicity. It should be noted that PPI and PAMAM dendrimers having the same number of surface amine groups do not share the same dendrimer generation. For example, both generation 4 PPI and generation 3 PAMAM dendrimers have 32 amine groups on their peripheries. Here, they were chosen as model dendrimers to compare the host behaviors of PPI and PAMAM dendrimers. Phenylbutazone was used as a model drug.

\section{Materials and methods Materials}

Generation 4 diaminobutane-cored and amine-terminated PPI dendrimer was purchased from Sigma-Aldrich (St Louis, MO). Generation 3-5 ethylenediamine-cored and amine-terminated PAMAM dendrimer was purchased from Dendritech Inc (Midland, MI). Phenylbutazone was purchased from Shangqiu Tiankang Fine Chemical Co, Ltd (Henan, China). Methanol of high-performance liquid chromatography (HPLC) grade was purchased from Fisher Scientific (Fair Lawn, NJ). Acridine orange and ethidium bromide were gifts from the School of Life Sciences,
East China Normal University. Deuterium oxide $\left(\mathrm{D}_{2} \mathrm{O}\right)$ was obtained from Beijing Chongxi High-Tech Incubator Co, Ltd (Beijing, China). Generation 3 PAMAM dendrimer was stored in methanol and the solvent was distilled before use. PAMAM and PPI dendrimers were prepared in aqueous solutions at a concentration of $10 \mathrm{mg} / \mathrm{mL}$, which were used as stock solutions. The dendrimers and the other chemicals were used as received without further purification.

\section{Phase solubility test}

The solubilities of hydrophobic drugs such as phenylbutazone in PAMAM and PPI dendrimer solutions were conducted using the Higuchi-Connors method as described elsewhere. ${ }^{25}$ A $2 \mathrm{mg}$ sample of phenylbutazone was added into $1.5 \mathrm{~mL}$ Eppendorf microtest tubes before the drug solubility test, followed by addition of PAMAM and PPI dendrimer solutions at different concentrations (dendrimer concentration ranges from 0.07 to $0.36 \mathrm{mM}$ ). The dendrimer-drug suspensions were shaken $(300 \mathrm{rpm})$ at room temperature for 24 hours to obtain a saturated phenylbutazone solution, and the mixtures were then centrifuged twice at $10,000 \mathrm{rpm}$ for 5 minutes to remove undissolved drugs. The drug concentrations in the supernatants were analyzed using an HPLC method.

\section{Gradient-feed method}

A $10 \mathrm{mg} / \mathrm{mL}$ phenylbutazone solution was prepared by dissolving the drug in methanol. Drug solutions $(40 \mu \mathrm{L})$ were added into Eppendorf microtest tubes, and the solvents in the tubes were removed to obtain phenylbutazone powder (0.4 $\mathrm{mg}$ in each tube). Herein, we used a gradient-feed method to compare the drug-loading abilities of PAMAM and PPI dendrimers. Generally, $4 \mathrm{~mL}$ of PAMAM or PPI solution $(0.14 \mathrm{mM})$ was added into a microtest tube containing $0.4 \mathrm{mg}$ phenylbutazone. The tube was then sonicated for 2 hours to ensure the drugs were dissolved in the dendrimer solution, followed by transfer of the mixture into a second tube with the same amount of phenylbutazone, and sonication of the dendrimer-drug mixture. The procedures were repeated until the solution was transferred into the twentieth tube. In each time interval, $10 \mu \mathrm{L}$ of the supernatant from the dendrimerdrug mixture was withdrawn from the tubes and analyzed by an HPLC method to determine the drug concentrations in the dendrimer solutions. Three repeats were conducted for each sample.

\section{HPLC method}

The samples were analyzed using a reverse-phase HPLC instrument (Agilent 1200, Agilent, Chicago, IL) with a 
C18 column (4.6 mm diameter, $150 \mathrm{~mm}$ length, $5 \mu \mathrm{m}$ particle size, Zorbax Eclipse XDB, Agilent) at $25^{\circ} \mathrm{C}$. The mobile phase was methanol and water at a ratio of $55: 45$ with a flow rate of $1.0 \mathrm{~mL} / \mathrm{minute}$. A volume of $10 \mu \mathrm{L}$ sample solution was injected and the phenylbutazone was detected at a wavelength of $264 \mathrm{~nm}$. The retention time of phenylbutazone is $3.8 \pm 0.3$ minute. Phenylbutazone solutions (methanol) at different concentrations were prepared to obtain a standard curve for the drug. The drug concentration correlated linearly with the peak area in HPLC ranges from 0.0005 to $0.01 \mathrm{mg} / \mathrm{mL}$ $(\mathrm{R}=0.9991)$.

\section{'H NMR and NOESY analysis}

${ }^{1} \mathrm{H}$ NMR and two-dimensional NOESY experiments were obtained on a Bruker Advance $500.132 \mathrm{mHz}$ NMR spectrometer at $298.2 \pm 0.2 \mathrm{~K}$ for dendrimers and dendrimer-drug complexes $(0.57 \mathrm{mM}$ generation 3 PAMAM or generation 4 PPI and $18 \mathrm{mM}$ phenylbutazone in $\mathrm{D}_{2} \mathrm{O}$ ).

Chemical shift assignments of the proton peaks in dendrimers and dendrimer-drug complexes are listed as follows. ${ }^{1} \mathrm{H}$ NMR for PPI dendrimer: 1.60 ppm $\left(120 \mathrm{H}\right.$, br, $-\mathrm{NCH}_{2}$ $\left.\underline{\mathrm{CH}}_{2} \mathrm{CH}_{2} \mathrm{~N}-, \mathrm{H}_{\mathrm{A}}\right) ; 2.44$ ppm $\left(116 \mathrm{H}, \mathrm{br},-\mathrm{NCH}_{2} \mathrm{CH}_{2} \underline{\mathrm{CH}}_{2} \mathrm{~N}-\right.$, $\left.\mathrm{H}_{\mathrm{B}}\right) ; 2.48 \mathrm{ppm}\left(64 \mathrm{H}, \mathrm{br},-\mathrm{NCH}_{2} \mathrm{CH}_{2} \mathrm{CH}_{2} \mathrm{NH}_{2}, \mathrm{H}_{\mathrm{B}^{\prime}}\right) ; 2.60 \mathrm{ppm}$ (64H, br, $-\mathrm{NCH}_{2} \mathrm{CH}_{2} \mathrm{CH}_{2} \mathrm{NH}_{2}, \mathrm{H}_{\mathrm{C}}$ ).

${ }^{1} \mathrm{H}$ NMR for PAMAM dendrimer: $2.39 \mathrm{ppm}(120 \mathrm{H}$, br, $\left.-\mathrm{NCH}_{2} \underline{\mathrm{CH}}_{2} \mathrm{CONH}-, \mathrm{H}_{\mathrm{a}}\right) ; 2.60 \mathrm{ppm}(56 \mathrm{H}$, br, $-\mathrm{CONH}$ $\left.\mathrm{CH}_{2} \underline{\mathrm{CH}}_{2} \mathrm{~N}-, \mathrm{H}_{\mathrm{b}}\right) ; 2.69$ ppm $\left(120 \mathrm{H}, \mathrm{br},-\mathrm{NCH}_{2} \mathrm{CH}_{2} \mathrm{CONH}-\right.$, $\left.\mathrm{H}_{\mathrm{c}}\right) ; 2.79 \mathrm{ppm}\left(64 \mathrm{H}, \mathrm{br},-\mathrm{CONHCH}_{2} \underline{\mathrm{CH}}_{2} \mathrm{NH}_{2}, \mathrm{H}_{\mathrm{b}^{\prime}}\right)$; $3.21 \mathrm{ppm}\left(56 \mathrm{H}, \mathrm{br},-\mathrm{CONHCH} \underline{\mathrm{CH}}_{2} \mathrm{~N}-, \mathrm{H}_{\mathrm{d}}\right) ; 3.26 \mathrm{ppm}(64 \mathrm{H}$, br, $-\mathrm{CONHCH} \underline{\mathrm{CH}}_{2} \mathrm{NH}_{2}, \mathrm{H}_{\mathrm{d}^{\prime}}$ ).

${ }^{1} \mathrm{H}$ NMR for PPI-phenylbutazone complex: $0.86 \mathrm{ppm}$ (3H, br, $\left.-\mathrm{CH}_{2} \mathrm{CH}_{3}, \mathrm{H}_{8}\right) ; 1.29$ ppm $\left(2 \mathrm{H}, \mathrm{br},-\mathrm{CH}_{2} \mathrm{CH}_{2} \mathrm{CH}_{3}, \mathrm{H}_{7}\right)$; 1.41 ppm $\left(2 \mathrm{H}, \mathrm{br},-\mathrm{CH}_{2} \underline{\mathrm{CH}}_{2} \mathrm{CH}_{2}-, \mathrm{H}_{6}\right) ; 1.57 \mathrm{ppm}(120 \mathrm{H}$, br, $\left.-\mathrm{NCH}_{2} \mathrm{CH}_{2} \mathrm{CH}_{2} \mathrm{~N}-, \mathrm{H}_{\mathrm{A}}\right) ; 2.14 \mathrm{ppm}\left(2 \mathrm{H}, \mathrm{br},-\mathrm{CH}-\underline{\mathrm{CH}}_{2}-\mathrm{CH}_{2}-\right.$, $\left.\mathrm{H}_{5}\right) ; 2.30$ ppm (116H, br, $\left.-\mathrm{NCH}_{2} \mathrm{CH}_{2} \underline{\mathrm{CH}}_{2} \mathrm{~N}-, \mathrm{H}_{\mathrm{B}}\right)$; $2.38 \mathrm{ppm}\left(64 \mathrm{H}, \mathrm{br},-\mathrm{NCH}_{2} \mathrm{CH}_{2} \mathrm{CH}_{2} \mathrm{NH}_{2}, \mathrm{H}_{\mathrm{B}^{\prime}}\right) ; 2.63 \mathrm{ppm}$ (64H, br, $-\mathrm{NCH}_{2} \mathrm{CH}_{2} \mathrm{CH}_{2} \mathrm{NH}_{2}, \mathrm{H}_{\mathrm{C}}$ ); 7.07 ppm (2H, br, Ar, $\left.\mathrm{H}_{1}\right)$; 7.24 ppm (4H, br, Ar, $\mathrm{H}_{3}$ ); 7.29 ppm (4H, br, Ar, $\mathrm{H}_{2}$ ).

${ }^{1} \mathrm{H}$ NMR for PAMAM-phenylbutazone complex: $0.85 \mathrm{ppm}$ (3H, br, $\left.-\mathrm{CH}_{2} \mathrm{CH}_{3}, \mathrm{H}_{8}\right) ; 1.28$ ppm $\left(2 \mathrm{H}, \mathrm{br},-\mathrm{CH}_{2} \mathrm{CH}_{2} \mathrm{CH}_{3}\right.$, $\left.\mathrm{H}_{7}\right) ; 1.40 \mathrm{ppm}\left(2 \mathrm{H}, \mathrm{br},-\mathrm{CH}_{2} \mathrm{CH}_{2} \mathrm{CH}_{2}-, \mathrm{H}_{6}\right) ; 2.14 \mathrm{ppm}(2 \mathrm{H}$, br, $\left.-\mathrm{CH}-\mathrm{CH}_{2}-\mathrm{CH}_{2}-\mathrm{H}_{5}\right) ; 2.30-2.35 \mathrm{ppm}\left(120 \mathrm{H}, \mathrm{br},-\mathrm{NCH}_{2}\right.$ $\left.\underline{\mathrm{CH}}_{2} \mathrm{CONH}-\mathrm{H}_{\mathrm{a}}\right) ; 2.50 \mathrm{ppm}\left(56 \mathrm{H}, \mathrm{br},-\mathrm{CONHCH}_{2} \underline{\mathrm{CH}}_{2} \mathrm{~N}-\right.$, $\left.\mathrm{H}_{\mathrm{b}}\right) ; 2.72 \mathrm{ppm}\left(120 \mathrm{H}, \mathrm{br},-\mathrm{NCH}_{2} \mathrm{CH}_{2} \mathrm{CONH}-, \mathrm{H}_{\mathrm{c}}\right) ; 2.89 \mathrm{ppm}$ $\left(64 \mathrm{H}, \mathrm{br},-\mathrm{CONHCH}_{2} \mathrm{CH}_{2} \mathrm{NH}_{2}, \mathrm{H}_{\mathrm{b}^{\prime}}\right) ; 3.19 \mathrm{ppm}(56 \mathrm{H}, \mathrm{br}$, $\left.-\mathrm{CONHCH} \underline{\mathrm{CH}}_{2} \mathrm{~N}-, \mathrm{H}_{\mathrm{d}}\right) ; 3.31 \mathrm{ppm}(64 \mathrm{H}, \mathrm{br},-\mathrm{CONH}$ $\left.\underline{\mathrm{CH}}_{2} \mathrm{CH}_{2} \mathrm{NH}_{2}, \mathrm{H}_{\mathrm{d}^{\prime}}\right) ; 7.08$ ppm $\left(2 \mathrm{H}, \mathrm{br}, \mathrm{Ar}, \mathrm{H}_{1}\right) ; 7.25$ ppm $\left(8 \mathrm{H}, \mathrm{br}, \mathrm{Ar}, \mathrm{H}_{2,3}\right)$.
For the two-dimensional NOESY experiment, $300 \mathrm{msec}$ was chosen as the mixing time for the optimization of cross-peak intensities with minimum distortions during the period for NOE establishment. A certain amount of ethanol was added to the dendrimer-drug solutions as an internal standard. A relaxation delay of one second, an acquisition time of $213 \mathrm{msec}$, and a $90^{\circ}$ pulse width of $7.7 \mu$ were used. Sixteen transients were collected over 800 complex points in the $t_{1}$ dimension. The data were processed by NMR Pipe software on a Linux system with standard Lorents-Gauss window function and zero filling in both dimensions. All data were shown with Sparky software.

\section{In vitro drug release studies}

The in vitro release behavior of phenylbutazone from PAMAM or PPI dendrimer matrixes in aqueous solutions was investigated. Dendrimer-phenylbutazone complexes were prepared by dissolving $1 \mathrm{mg}$ drug in $2 \mathrm{~mL} 0.14 \mathrm{mM}$ generation 3 PAMAM or generation 4 PPI dendrimer solutions. The dendrimer-drug mixture was sonicated for 2 hours and transferred into a dialysis bag with a molecular weight cutoff of $1000 \mathrm{Da}$, which was immediately immersed into $50 \mathrm{~mL}$ distilled water. The molecular weights for generation 3 PAMAM and generation 4 PPI dendrimers are $6900 \mathrm{Da}$ and $3513 \mathrm{Da}$, respectively. The dendrimers and dendrimer-drug complexes were kept inside the dialysis bag while the free phenylbutazone molecules with a molecular weight of $308 \mathrm{Da}$ released into the outer phase of the dialysis bag. At specific time intervals, $30 \mu \mathrm{L}$ samples were withdrawn from the outer phase which was replenished with $30 \mu \mathrm{L}$ distilled water. The phenylbutazone concentrations in the samples were analyzed using the HPLC method. Three repeats were conducted for each sample.

\section{Cell culture and cytotoxicity assay}

MCF-7 and A549 cells (American Type Culture Collection, Manassus, VA) were incubated at $37^{\circ} \mathrm{C}$ in $5 \% \mathrm{CO}_{2}$ and Dulbecco's modified Eagle's medium (DMEM, Gibco Inc, Carlsbad, CA) supplemented with streptomycin $100 \mu \mathrm{g} / \mathrm{mL}$, penicillin sulfate $100 \mathrm{U} / \mathrm{mL}$, and $10 \%$ heat-inactivated fetal calf serum (Gibco Inc). The cytotoxicity of generation 3 PAMAM and generation 4 PPI dendrimers on both cells were evaluated using a 3-(4,5-dimethythiazol-2-yl)-2,5diphenyl tetrazolium bromide (MTT) assay, which is the most frequently used method for measuring cell proliferation and viability. MCF-7 or A549 cells were seeded in 96-well culture plates for 48 hours at a density of $10^{4}$ cells per well before the cytotoxicity assay. After that, the cells were treated 
with DMEM containing different concentrations of PAMAM or PPI dendrimers (dendrimer concentration ranges from $3.62 \times 10^{-7} \mathrm{M}$ to $7.25 \times 10^{-5} \mathrm{M}$ ) for 48 hours, followed by removal of the medium, washing of the MCF-7 or A549 cells twice with fresh phosphate-buffered saline, and incubation of the cells with DMEM containing MTT for 3 hours. The MTT dye was reduced to purple formazan in living cells and the formazan generated was dissolved by dimethylsulfoxide. Absorbance of the solution in each well was measured at $570 \mathrm{~nm}$ using a microplate reader (MQX200R, Bio-Tek Instruments Inc, Winooski, VT). The cells that received no dendrimer were set as positive controls to $100 \%$ viability. The viabilities of the PAMAM and PPI dendrimers were expressed as a percentage of the control. Six repeats were conducted for each sample.

Acridine orange and ethidium bromide were used for morphological detection of apoptotic and necrotic cells. ${ }^{26}$ MCF-7 and A549 cells were seeded in 24-well plates and cultured in the absence or presence of dendrimers $(14.5 \mu \mathrm{M}$ PAMAM or PPI dendrimer in DMEM) for 12 hours before the acridine orange/ethidium bromide double staining experiment. The cells were rinsed in phosphate-buffered saline twice and incubated in acridine orange/ethidium bromide containing phosphate-buffered saline $(5 \mu \mathrm{g} / \mathrm{mL}$ acridine orange and $5 \mu \mathrm{g} / \mathrm{mL}$ ethidium bromide) at $37^{\circ} \mathrm{C}$ in $5 \% \mathrm{CO}_{2}$ for 10 minutes. The stained cells were then imaged using a fluorescence microscope (Moticam 5000, Motic Instruments Inc, Richmond, Canada).

\section{Results and discussion Drug loading ability of PAMAM and PPI dendrimers}

Phenylbutazone is a nonsteroidal anti-inflammatory drug for the long-term treatment of chronic pain particularly due to osteoarthritis and rheumatoid arthritis. It has an extremely low solubility of around $74 \mu \mathrm{M}$ in distilled water, indicating low bioavailability by oral administration route and challenges in preparation of injections. Here phenylbutazone is used as a model drug to evaluate the drug-loading ability of PAMAM and PPI dendrimers. As shown in Figure 1, the solubility of phenylbutazone was enhanced by a factor of 126 in the presence of $0.36 \mathrm{mM}$ generation 3 PAMAM dendrimer, suggesting that an average number of 26 drug molecules were bound by each dendrimer. The solubility of phenylbutazone in PAMAM dendrimer solution is linear with dendrimer concentration due to increasing surface amine groups and interior pockets. Surprisingly, PPI dendrimer at a concentration

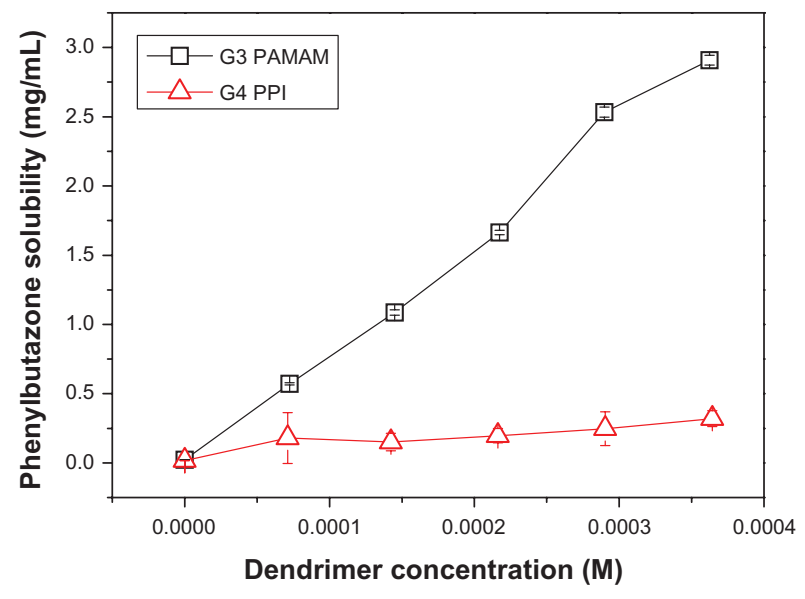

Figure I Solubility enhancement of phenylbutazone in the presence of generation 3 PAMAM and generation 4 PPI dendrimers.

Abbreviations: PAMAM, polyamidoamine; PPI, polypropylenimine.

of $0.36 \mathrm{mM}$ only enhances phenylbutazone solubility by 13 times, and the solubilization behavior scarcely increases with dendrimer concentration. Our previous studies have demonstrated that surface amine groups play important roles in drug binding and the surface ionic interactions contribute much more to the solubility enhancement of drugs than interior encapsulations by hydrophobic and hydrogen bond interactions. ${ }^{13}$ Here, both generation 4 PPI and generation 3 PAMAM dendrimers have 32 primary amine groups on their surface. The $\mathrm{pKa}$ values for these surface amine groups are $9.75^{17}$ and $10.5^{27}$ for PPI and PAMAM dendrimers, respectively, and the $\mathrm{pH}$ value of the dendrimer-drug solution is in the range of 5.3-6.0 for PPI and 6.3-7.0 for PAMAM depending on the ratio of dendrimer and drug in the solution, suggesting that all the amine groups are protonated and the numbers of charged surface functionalities for both dendrimers are equal to each other. Therefore, the distinct solubilization behaviors of PAMAM and PPI dendrimers cannot be interpreted by the number of surface charges.

Interior hydrophobicity, pocket volume, amido groups, and surface charge densities should be considered in addition to surface charge. With regard to interior hydrophobicity, generation 4 PPI has a much more hydrophobic interior than generation 3 PAMAM, suggesting that PPI should be able to encapsulate more drugs in its interior pockets than PAMAM, ${ }^{16,28}$ which is opposite to the results shown in Figure 1. For pocket volume, it is known that the length of branching units for constructing PPI dendrimer is much shorter than that for PAMAM dendrimer (4-bond versus 7-bond), thereby the size of generation 4 PPI is much smaller than that of generation 3 PAMAM 
(molecular weight 3513 Da versus 6900 Da; size $2.3 \mathrm{~nm}^{29}$ versus $3.0 \mathrm{~nm}^{1}$ ). A larger dendrimer size or pocket volume of PAMAM is likely to encapsulate more drug molecules. Further, the amido groups in the scaffold of PAMAM (60 amido groups in each generation 3 PAMAM) may facilitate the encapsulation of phenylbutazone molecules via hydrogen bond interactions (N-H in the amido group as hydrogen bond donor and oxygen atoms in phenylbutazone as receptors). ${ }^{21}$ However, the effects of pocket volume and amido groups should be ruled out because more phenylbutazone molecules were found in the cavities of PPI dendrimer, which is evident by NOESY analysis and will be further discussed in the next sections. Finally, with regard to surface charge density, PPI with a smaller molecular size had a higher surface charge density than PAMAM $\left(19.3 \times 10^{-3} / \AA^{2}\right.$ versus $\left.11.3 \times 10^{-3} / \AA^{2}\right)$. Higher charge density on the globular surface of PPI dendrimer means steric hindrance during ionic binding which may decrease the amount of drug bound on the dendrimer surface. However, surface charge density was found to have a limited influence on the drug-loading ability of the dendrimer in our previous studies and cannot be a predominant factor in the distinct solubilization behaviors of PAMAM and PPI dendrimers towards phenylbutazone. ${ }^{25,30}$

A reasonable interpretation is that PPI and phenylbutazone complex is not stable in aqueous solution and may precipitate from the solution. This is confirmed by the disappearance of PPI dendrimer peaks in the ${ }^{1} \mathrm{H}$ NMR spectra of the supernatant of PPI-phenylbutazone mixtures from aqueous solubility studies (data not shown). A possible reason for the precipitation of PPI-phenylbutazone complexes is that the PPI dendrimer is an amphiphilic macromolecule with a hydrophobic interior. ${ }^{17}$ Attachment of phenylbutazone molecules on the PPI surface via ionic interaction neutralizes the surface charges of the dendrimer, forming hydrophobic nanostructures with low aqueous solubility. Another reason is that phenylbutazone encapsulated in the congested pockets of PPI dendrimer may interact with the alkyl chain of PPI by strong hydrophobic interactions, resulting in collapse of the dendritic scaffold into hydrophobic pellets and precipitation of the PPI-phenylbutazone complex from the solution. ${ }^{22}$ Perhaps a combined effect of the two factors contributes to precipitation of the complex. In the case of the PAMAM dendrimer, its interior cavities are much larger than those of PPI and the microenvironment of PAMAM is relatively hydrophilic, which make drug complexes with PAMAM more soluble than those with PPI in aqueous solutions.
Precipitation of PPI-phenylbutazone complexes and stability of the PAMAM-phenylbutazone complex were further confirmed by a gradient-feed method.

\section{Drug-loading ability of PAMAM and PPI dendrimers}

Using the gradient-feed method, equivalent amounts of phenylbutazone were added into the dendrimer solutions in a stepwise manner rather than single addition of excess drugs in the phase solubility test. As shown in Figure 2, a similar amount of phenylbutazone was bound by PAMAM and PPI dendrimers at the initial steps of the gradient-feed experiment. The drugs solubilized by both dendrimers increased linearly with the total amount of added drugs at this stage, which is attributed to the equivalent number of surface charges and interior pockets for generation 3 PAMAM and generation 4 PPI dendrimer. A maximum amount of phenylbutazone (2.4 mg) solubilized by PPI dendrimer was obtained at the ninth step when a cumulative amount of $3.6 \mathrm{mg}$ phenylbutazone was fed, and a remarkable decrease in the amount of solubilized drug by PPI was observed in the following steps. The drug concentration decreased to $0.11 \mathrm{mg} / \mathrm{mL}$ which is slightly higher than the solubility of phenylbutazone in distilled water at the twentieth step, and white particles were found on the walls of the microtest tubes, suggesting precipitation of PPI-drug complexes during this period. As discussed above, precipitation of PPI and phenylbutazone complexes is caused by neutralization of surface charges on the surface of PPI dendrimer with a hydrophobic interior and/or the collapse of PPI scaffolds by strong hydrophobic interactions. The phenylbutazone amount of $2.4 \mathrm{mg}$ can be recognized as the maximum drug-loading capacity for $0.14 \mathrm{mM}$ generation 4 PPI dendrimer in $4 \mathrm{~mL}$ water. In the case of the PAMAM dendrimer, the amount of phenylbutazone dissolved in dendrimer solution linearly increases from 0.28 to $3.6 \mathrm{mg}$ in the first 13 steps, followed by a slight increase in drug concentration, and the drug does not reach its saturation point in PAMAM solution even at the twentieth step. Therefore, the PAMAM-phenylbutazone complex is much more stable than the PPI-drug complex in aqueous solution, which explains the difference in solubilization behavior between the PAMAM and the PPI dendrimer in the phase solubility studies. It is concluded that the results obtained from phase solubility studies cannot fully clarify the loading ability of the dendrimer, given that the PPI dendrimer failed to enhance the solubility of phenylbutazone greatly, but exhibited high drug-loading efficiency before a maximum loading amount was achieved in the gradient-feed experiment. 


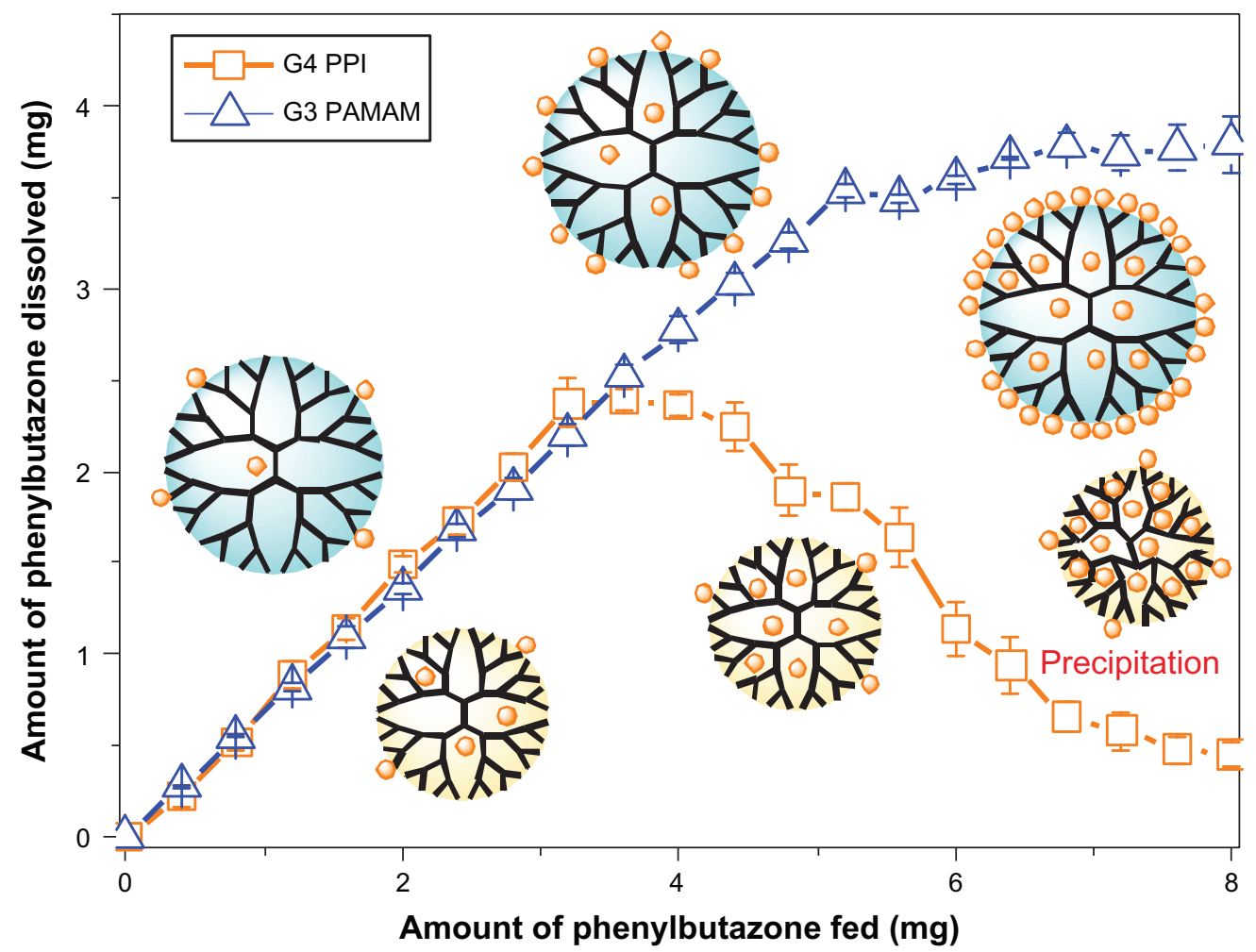

Figure 2 Comparison of drug-loading ability of generation 3 PAMAM and generation 4 PPI dendrimers using a gradient-feed method. Abbreviations: PAMAM, polyamidoamine; PPI, polypropylenimine.

\section{Characterization of PAMAM- phenylbutazone and PPI-phenylbutazone}

To clarify the structural differences between PAMAM and PPI dendrimers and their influence on drug-loading, ${ }^{1} \mathrm{H}$ NMR and NOESY spectra of the dendrimers and their complexes with phenylbutazone were obtained. As shown in Figure 3, generation 4 PPI dendrimer has four groups of peaks in $\mathrm{D}_{2} \mathrm{O}$ which are assigned as protons $\mathrm{H}_{\mathrm{A}}, \mathrm{H}_{\mathrm{B}^{\prime}}, \mathrm{H}_{\mathrm{B}^{\prime}}$ and $\mathrm{H}_{\mathrm{C}}$, respectively, while generation 3 PAMAM dendrimers has six groups of peaks which are assigned as $\mathrm{H}_{\mathrm{a}}, \mathrm{H}_{\mathrm{b}}, \mathrm{H}_{\mathrm{b}}, \mathrm{H}_{\mathrm{c}}, \mathrm{H}_{\mathrm{d}}$, and $\mathrm{H}_{\mathrm{d}}$, respectively. ${ }^{3,18}$ Protons $\left(\mathrm{H}_{\mathrm{c}}\right)$ of PPI and protons $\left(\mathrm{H}_{\mathrm{b}^{\prime}}\right.$ and $\left.\mathrm{H}_{\mathrm{d}^{\prime}}\right)$ of PAMAM exhibit significant downfield shifts in dendrimerphenylbutazone complexes as compared with that in free dendrimers. In addition, significant upfield shifts for other protons of PPI and PAMAM dendrimers are observed in the complexes. Previous studies have demonstrated that downfield shift of the methylene protons located on the surface of amine-terminated PAMAM dendrimer is attributed to the ionic binding of guests on dendrimer surface (decreased electron density around these protons) and upfield shift of the interior methylene protons in PAMAM pockets might be caused by the hydrophobic encapsulations of the guests (increased electron density around these protons). ${ }^{21}$ The shift behaviors of protons in PAMAM and PPI dendrimers in the presence of phenylbutazone prove the roles of ionic interactions and interior encapsulations in the formation of dendrimer-phenylbutazone complexes.

The encapsulations of phenylbutazone molecules in generation 3 PAMAM and generation 4 PPI dendrimers are investigated by a ${ }^{1} \mathrm{H}-{ }^{1} \mathrm{H}$ NOESY study, which is always used to analyze the spatial distance between specific protons. ${ }^{21}$ The presence of NOE cross-peaks between two protons in NOESY spectrum indicates the spatial proximity of these protons, and the cross-peak intensity decreases with spatial distance, and increases with the number of molecules involved in the cross-peak. ${ }^{3,31}$ As shown in Figure 4A, strong cross-peaks between aromatic protons $\left(\mathrm{H}_{1-3}\right)$ and the interior methylene protons $\left(\mathrm{H}_{\mathrm{A}}\right.$ and $\left.\mathrm{H}_{\mathrm{B}}\right)$ are observed, confirming that phenylbutazone molecules are encapsulated in the pockets of PPI dendrimer. The absence of cross-peaks between the protons $\left(\mathrm{H}_{\mathrm{B}^{\prime}}\right.$ and $\left.\mathrm{H}_{\mathrm{C}}\right)$ of PPI and phenylbutazone suggests that most of the drugs are located deep inside the interior of PPI, and this phenomenon is in accordance with our previous findings on PAMAM-drug complexes as well as the NOESY results for PAMAM-phenylbutazone complexes shown in Figure 4B. ${ }^{21}$ The negative NOE cross-peaks between the aromatic protons $\left(\mathrm{H}_{1-3}\right)$ and the alkyl protons $\left(\mathrm{H}_{5-8}\right)$ of phenylbutazone further demonstrate the bound of drug molecules by PPI 


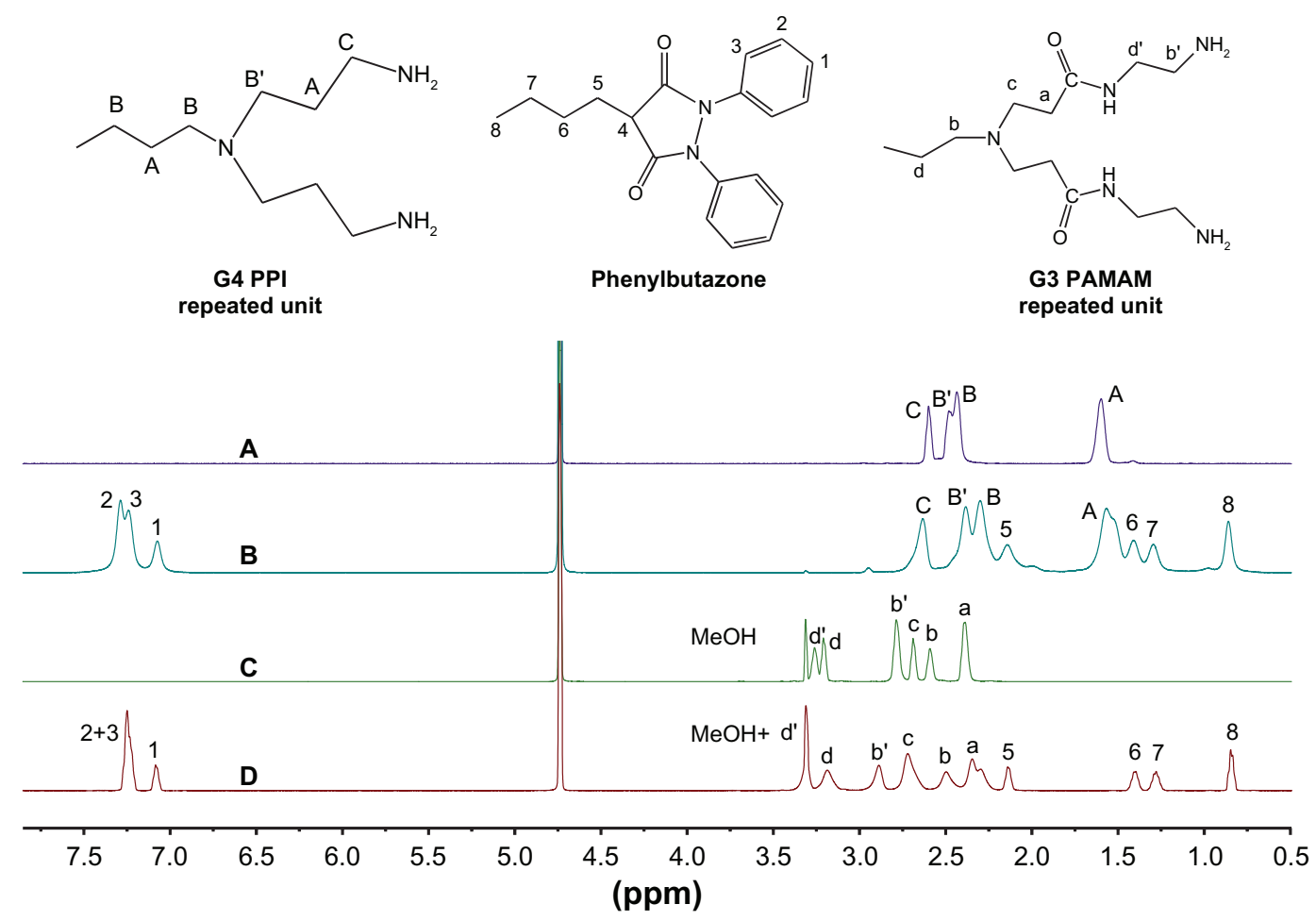

Figure 3 'H Nuclear magnetic resonance spectra of dendrimer and dendrimer-phenylbutazone complexes. (A) generation 4 PPI, (B) generation 4 PPI-phenylbutazone complex, (C) generation 3 PAMAM, and (D) generation 3 PAMAM-phenylbutazone complex.

Abbreviations: PAMAM, polyamidoamine; PPI, polypropylenimine.

dendrimer. ${ }^{3,25}$ In case of PAMAM-phenylbutazone complex, cross-peaks between PAMAM and phenylbutazone are found between $\mathrm{H}_{\mathrm{a}-\mathrm{d}}$ of PAMAM and $\mathrm{H}_{2,3}$ of phenylbutazone. The absence of cross-peaks between $\mathrm{H}_{1}$ and $\mathrm{H}_{\mathrm{a}-\mathrm{d}}$ and the absence of cross-peaks between $\mathrm{H}_{1}$ and $\mathrm{H}_{5-8}$ indicate that the drugs and dendritic scaffold are more distant from each other than that in PPI-phenylbutazone complex. This is attributed to the fact that PPI has a more hydrophobic interior than PAMAM. The ${ }^{1} \mathrm{H}$ NMR and NOESY analysis concluded that both ionic interaction and interior encapsulation play important roles in the formations dendrimer-phenylbutazone complexes. The neutralization of surface charges on PPI surface via ionic interactions and the collapse of PPI structure due to strong hydrophobic interactions may lead to the precipitation of PPI-phenylbutazone complexes which is confirmed in a previous section.

\section{Release behavior of phenylbutazone from PAMAM and PPI complexes}

To reveal further the structure differences in PAMAM and PPI dendrimer, in vitro release behaviors of phenylbutazone from PAMAM and PPI matrixes were investigated. As shown in Figure 5, generation 3 PAMAM dendrimer shows better sustained release ability than generation 4 PPI dendrimer, ie, only $13 \%$ of the drug was found in outer phase of the dialysis bag after 12 hours for PAMAM, while $44 \%$ of the drug released from PPI-drug complex during the same period. In phase solubility and gradient-feed experiments, the generation 3 PAMAM dendrimer shows better capacity in loading phenylbutazone molecules compared with the generation 4 PPI dendrimer at high phenylbutazone/dendrimer feeding ratios, and the generation 3 PAMAM-phenylbutazone complex is much more stable in aqueous solution than in the generation 4 PPI-phenylbutazone complex. Therefore, a faster release of phenylbutazone was obtained from PPI than from PAMAM. Drug carriers with ideal sustained release behavior can improve drug bioavailability, decrease side effects of a drug at a high concentration, simplify the dosing schedule, and are beneficial for practical applications. ${ }^{32}$ A PAMAM dendrimer which exhibits a much slower release rate for phenylbutazone should be a better candidate in the development of dendrimer-phenylbutazone formulations than PPI dendrimer. Perhaps chemical modification of PPI surface with hydrophilic moieties such as PEG chains and acetyl groups may increase the stability of the dendrimer-drug complex, improve solubility and delivery efficacy of the PPI dendrimer, ${ }^{33}$ and solve the 

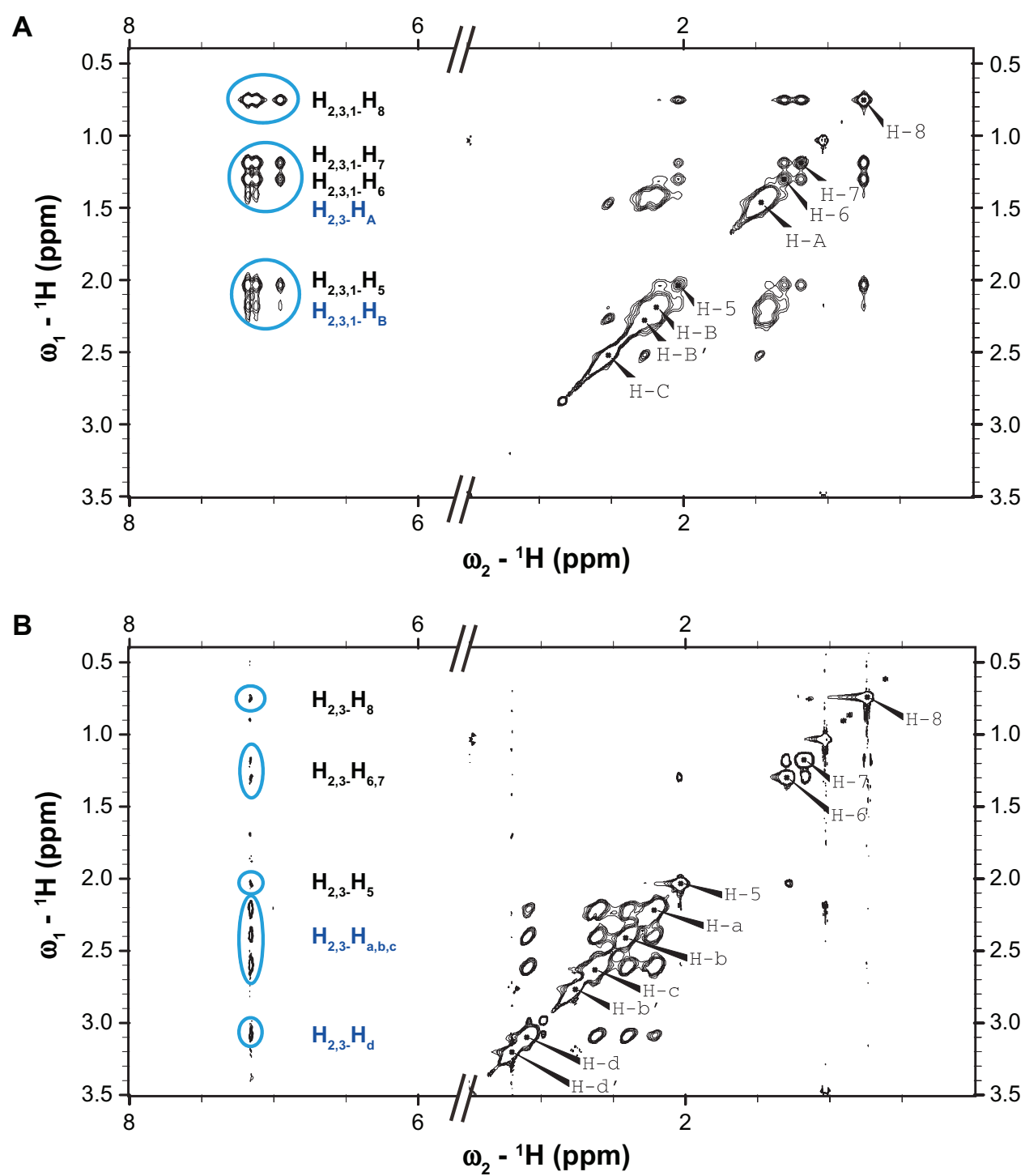

Figure 4 ' $\mathrm{H}$-' $\mathrm{H}$ nuclear Overhauser effect spectra of dendrimer-phenylbutazone complexes. (A) Generation 4 PPI and (B) generation 3 PAMAM dendrimer. Abbreviations: PAMAM, polyamidoamine; PPI, polypropylenimine.

serious toxicity problem of the PPI dendrimer which will be discussed in the next section.

\section{Comparison of cytotoxicity on PAMAM and PPI dendrimers}

An MTT assay was conducted to compare the cytotoxicity of PAMAM and PPI dendrimers. Figure 6A shows the toxicity of PAMAM and PPI dendrimers in A549 cells. Generation 3 PAMAM is not toxic at concentrations up to $72 \mu \mathrm{M}$, while generation 4 PPI exhibits cytotoxicity at a concentration of $1.4 \mu \mathrm{M}$, suggesting that generation $4 \mathrm{PPI}$ is at least 50 times more toxic to A549 cells than generation 3 PAMAM. Similar results were obtained for MCF-7 cells as shown in Figure 6B. The $\mathrm{IC}_{50}$ values of generation 4 PPI dendrimer in A549 and
MCF-7 cells are $4.3 \mu \mathrm{M}$ and $4.1 \mu \mathrm{M}$, respectively. An acridine orange/ethidium bromide double staining method was also used to compare the cytotoxicity of PAMAM and PPI dendrimers. ${ }^{26}$ As shown in Figure 7, A549 and MCF-7 cells incubated with generation 3 PAMAM are viable (green), but cells treated with generation 4 PPI dendrimer at an equivalent molar concentration are found at a lower cell density and cells in necrosis with orange nuclei. Previous studies have found that primary amine groups on the dendrimer surface interact with phospholipids in the cell membrane ${ }^{33}$ followed by disturbance of these amphiphilic molecules and formation of holes in the cell membrane, resulting in leakage of intracellular components..$^{34}$ Cationic dendrimers were reported to destroy mitochondrial membranes, leading to the generation of reactive oxygen species 


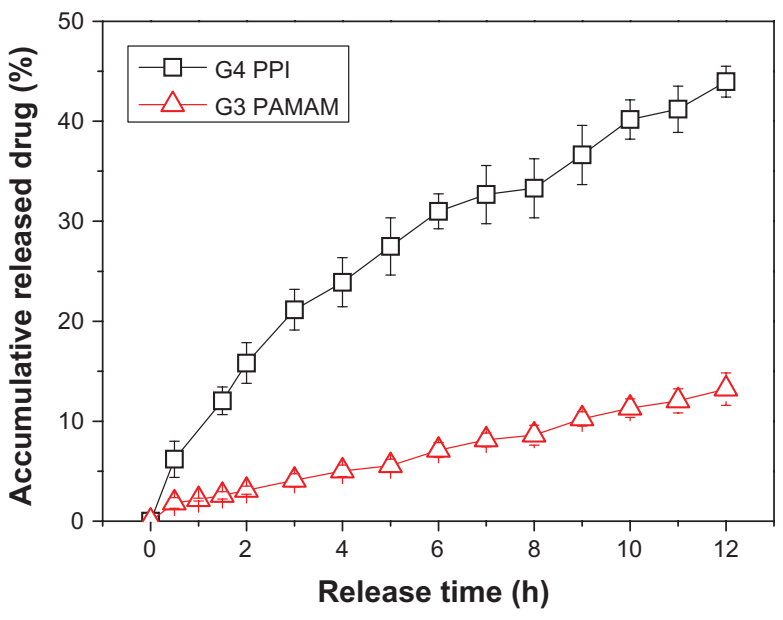

Figure 5 Release behavior of phenylbutazone from generation 3 PAMAM and generation 4 PPI dendrimers.

Abbreviations: PAMAM, polyamidoamine; PPI, polypropylenimine.

causing oxidative stress, DNA damage, and apoptosis. ${ }^{35,36}$ The removal of surface amine groups by acetylation or PEGylation can effectively decrease the cytotoxicity of PAMAM and PPI dendrimers, ${ }^{23,37}$ indicating that surface charge plays an important role in the cytotoxicity of both dendrimers. ${ }^{34}$ Generation 3
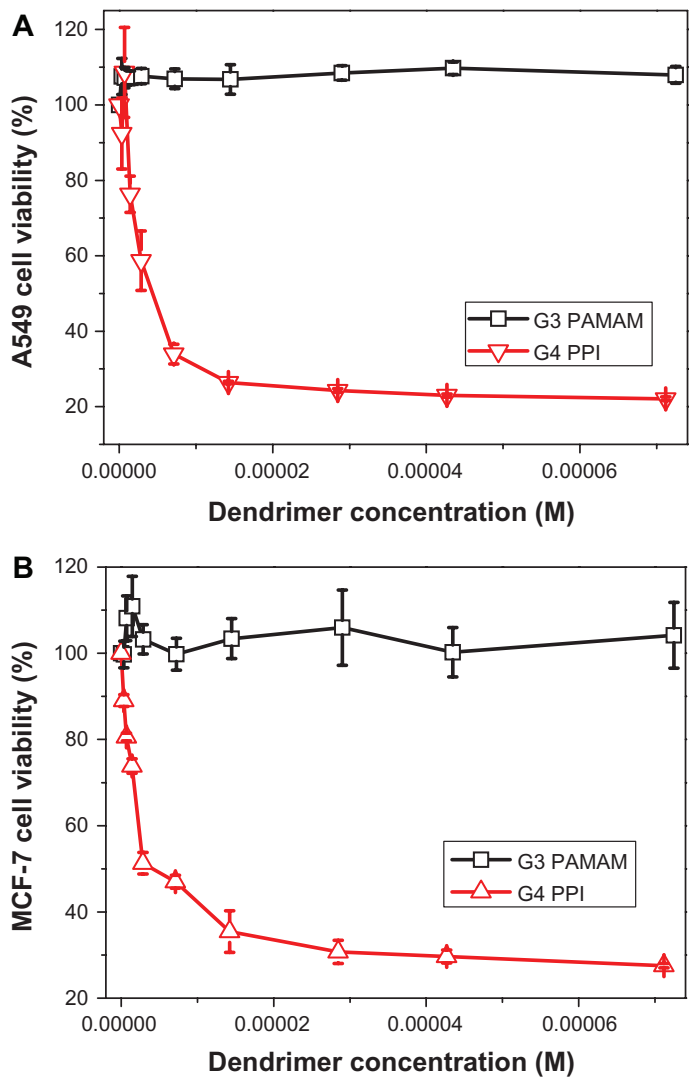

Figure 6 Viability of A549 cells (A) and MCF-7 cells (B) incubated with different concentrations of generation 3 PAMAM and generation 4 PPI dendrimers for 48 hours.

Abbreviations: PAMAM, polyamidoamine; PPI, polypropylenimine.
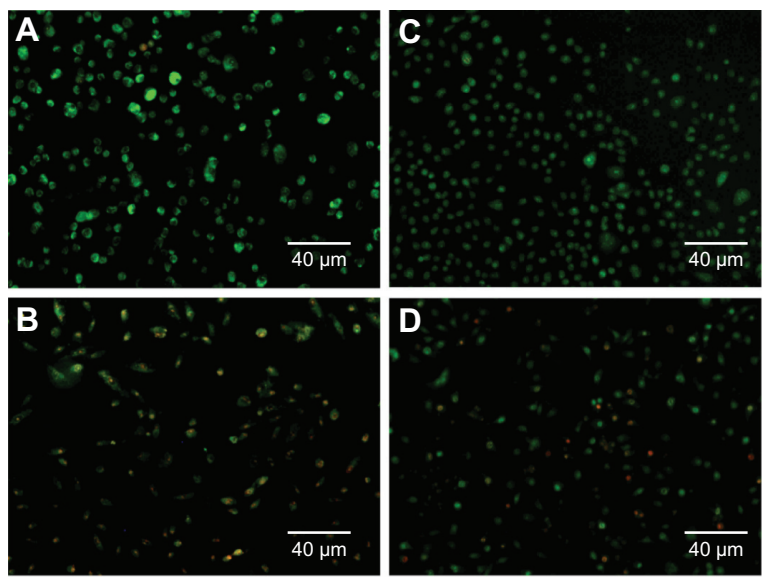

Figure 7 Images of A549 (A and B) and MCF-7 cells (C and D) incubated with generation 3 PAMAM (A and $\mathbf{C})$, or generation 4 PPI (B and $\mathbf{D})$ for 12 hours at a concentration of $14.5 \mu \mathrm{M}$.

Abbreviations: PAMAM, polyamidoamine; PPI, polypropylenimine.

PAMAM and generation 4 PPI have equivalent numbers of primary amine groups ( $\mathrm{pKa}$ about 10 ) which are fully protonated under physiological conditions ( $\mathrm{pH}$ about 7.4). Also, they have a similar $\mathrm{pH}$-buffering capacity due to the same amount of tertiary amine groups, indicating similar escape abilities for PAMAM and PPI from endosomes after cellular uptake. ${ }^{37}$ Therefore, other factors including dendrimer size and interior hydrophobicity, are proposed to explain the distinct viability of cells in the presence of generation 3 PAMAM and generation 4 PPI. Dendrimer cytotoxicity was found to be proportional to dendrimer size or generation in many cell lines, ${ }^{34}$ ie, generation 4 and 5 PAMAM dendrimers show much higher cytotoxicity to MCF-7 cells than generation 3 PAMAM dendrimers at an equivalent concentration of surface charge (Figure 8). Also, high-generation PPI dendrimer displayed higher cytotoxicity

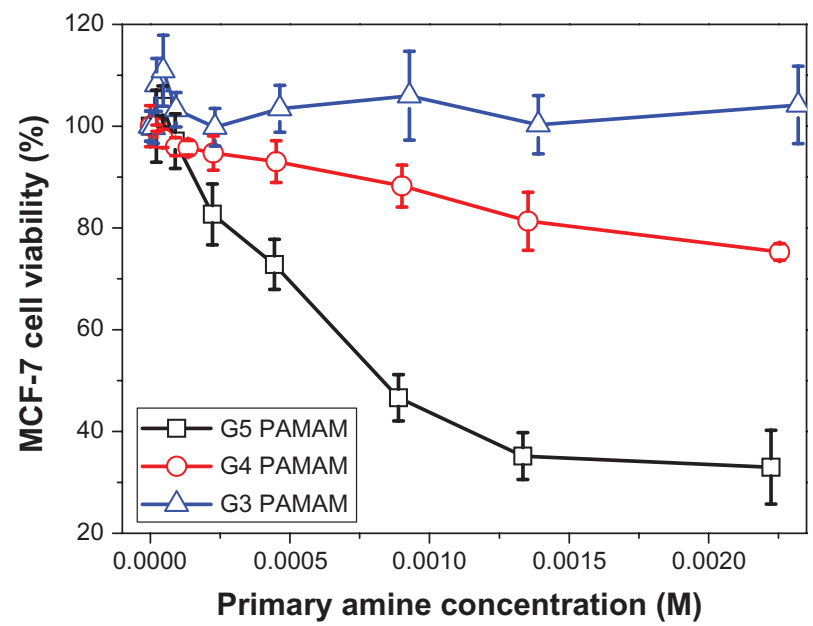

Figure 8 Viability of MCF-7 cells incubated with generation 3, generation 4, and generation 5 PAMAM dendrimers at different concentrations for 48 hours. Abbreviation: PAMAM, polyamidoamine. 
Table I A systematic comparison of G3 PAMAM and G4 PPI dendrimers on their physicochemical properties, drug loading, stability, complex structure, release rate, and cytotoxicity

\begin{tabular}{|c|c|c|}
\hline Dendrimer & G3 PAMAM & G4 PPI \\
\hline Molecular weight (Da) & 6900 & 3513 \\
\hline $\begin{array}{l}\text { Number of surface amine } \\
\text { groups }\end{array}$ & 32 & 32 \\
\hline Hydrodynamic radius (nm) & 3.0 & 2.3 \\
\hline Interior pockets & Relatively polar & Non-polar \\
\hline $\begin{array}{l}\text { Phenylbutazone } \\
\text { loading }\end{array}$ & High & $\begin{array}{l}\text { High at low drug/ } \\
\text { dendrimer ratio }\end{array}$ \\
\hline $\begin{array}{l}\text { Main binding } \\
\text { mechanism }\end{array}$ & $\begin{array}{l}\text { Surface ionic } \\
\text { interaction }\end{array}$ & Inclusion structure \\
\hline Complex stability & Excellent & Poor \\
\hline Release rate & Slow & Relatively rapid \\
\hline Cytotoxicity & Low toxic & Toxic \\
\hline
\end{tabular}

Abbreviations: PAMAM, polyamidoamine; PPI, polypropylenimine.

than low-generation PPI dendrimer on many cell lines. ${ }^{34,38}$ In that situation, generation 4 PPI should be more biocompatible than generation 3 PAMAM with a larger size and equivalent amount of surface charge. Perhaps the unique hydrophobic interior of PPI plays an important role in the serious toxicity of the PPI dendrimer. Detailed mechanisms for this interesting phenomenon are still under investigation.

\section{Conclusion}

In the present study, we compared the drug loading ability, release behavior, and cytotoxicity of generation 3 PAMAM and generation 4 PPI dendrimers. As shown in Table 1, generation 3 PAMAM showed better performance in solubilization and release of phenylbutazone molecules than did generation 4 PPI with the same number of surface amine groups. Also, generation 4 PPI dendrimer was at least 50 times more toxic than generation 3 PAMAM dendrimer to MCF-7 and A549 cells. The generation 4 PPIphenylbutazone complex is not as stable as the generation 3 PAMAM-phenylbutazone complex and precipitates from aqueous solution above the maximum loading capacity. NMR studies confirmed strong hydrophobic interactions between phenylbutazone molecules and dendritic scaffolds in the interior pockets of the generation 4 PPI dendrimer, which is proposed to be the major reason behind precipitation of the generation 4 PPI-phenylbutazone complex. In conclusion, generation 3 PAMAM dendrimers are better candidates for development of a phenylbutazone formulation, while generation 4 PPI dendrimers should be surface-modified to improve their performance in terms of drug-loading and release and to solve their toxicity problems before being used as drug carriers. ${ }^{39}$

\section{Acknowledgments}

We thank the Talent Program of East China Normal University (77202201), the "Dawn" Program of Shanghai Education Commission (10SG27), and the 2010 Open Foundation of the CAS Key Laboratory for Biomedical Effects of Nanomaterials and Nanosafety for supporting this research.

\section{Disclosure}

The authors report no conflicts of interest in this work.

\section{References}

1. Tomalia DA. Birth of a new macromolecular architecture: dendrimers as quantized building blocks for nanoscale synthetic polymer chemistry. Prog Polym Sci. 2005;30:294-324.

2. Menjoge AR, Kannan RM, Tomalia DA. Dendrimer-based drug and imaging conjugates: design considerations for nanomedical applications. Drug Discov Today. 2010;15:171-185.

3. Zhao LB, Wu QL, Cheng YY, Zhang JH, Wu JH, Xu TW. High-throughput screening of dendrimer-binding drugs. J Am Chem Soc. 2010;132:13182-13184.

4. Astruc D, Boisselier E, Ornelas C. Dendrimers designed for functions: from physical, photophysical, and supramolecular properties to applications in sensing, catalysis, molecular electronics, photonics, and nanomedicine. Chem Rev. 2010;110:1857-1859.

5. Cheng YY, Xu TW. The effect of dendrimers on the pharmacodynamic and pharmacokinetic behaviors of non-covalently or covalently attached drugs. Eur J Med Chem. 2008;43:2291-2297.

6. Gillies ER, Frechet JMJ. Dendrimers and dendritic polymers in drug delivery. Drug Discov Today. 2005;10:35-43.

7. Zhang YQ, Sun YH, Xu XP, et al. Synthesis, biodistribution, and microsingle photon emission computed tomography (SPECT) imaging study of technetium-99m labeled PEGylated dendrimer poly(amidoamine) (PAMAM)-folic acid conjugates. J Med Chem. 2010;53:3262-3272.

8. Zhang YQ, Sun YH, Xu XP, et al. Radiosynthesis and micro-SPECT imaging of $99 \mathrm{~m} \mathrm{Tc}$-dendrimer poly(amido)-amine folic acid conjugate. Bioorg Med Chem Lett. 2010;20:927-931.

9. Xu XP, Zhang YQ, Wang X, et al. Radiosynthesis, biodistribution and micro-SPECT imaging study of dendrimer-avidin conjugate. Bioorg Med Chem. 2011;19:1643-1648.

10. Mintzer MA, Grinstaff MW. Biomedical applications of dendrimers: a tutorial. Chem Soc Rev. 2011;40:173-190.

11. Tomalia DA, Baker H, Dewald J, et al. A new class of polymers: starburst-dendritic macromolecules. Polym J. 1985;17:117-132.

12. de Brabander van den Berg EMM, Meijer EW. Poly(propylene imine) dendrimers: large-scale synthesis by heterogeneously catalyzed hydrogenations. Angew Chem Int Ed. 1993;32:1308-1311.

13. Cheng YY, Wu QL, LiYW, Xu TW. External electrostatic interaction versus internal encapsulation between cationic dendrimers and negatively charged drugs: which contributes more to solubility enhancement of the drugs? J Phys Chem B. 2008;112:8884-8890.

14. Naylor AM, Goddard III WA, Kiefer GE, Tomalia DA. Starburst dendrimers. 5. molecular shape control. J Am Chem Soc. 1989;111: 2339-2341.

15. Cheng YY, Li YW, Wu QL, Xu TW. New insights into the interactions between dendrimers and surfactants by two dimensional NOE NMR spectroscopy. J Phys Chem B. 2008;112:12674-12680.

16. Richter-Egger DL, Tesfai A, Tucker SA. Spectroscopic investigations of poly(Propyleneimine) dendrimers using the solvatochromic probe phenol blue and comparisons to poly(amidoamine) dendrimers. Anal Chem. 2001;73:5743-5751. 
17. Kannaiyan D, Imae T. pH-dependent encapsulation of pyrene in PPI-core: PAMAM-shell dendrimers. Langmuir. 2009;25:5282-5285.

18. Boisselier E, Liang L, Dalko-Csiba M, Ruiz J, Astruc D. Interactions and encapsulations vitamins $\mathrm{C}, \mathrm{B}_{3}$, and $\mathrm{B}_{6}$ with dendrimer in water. Chem Eur J. 2010;16:6056-6068.

19. Haba Y, Harada A, Takagishi T, Kono K. Rendering poly(amidoamine) or poly(propylenimine) dendrimers temperature sensitive. J Am Chem Soc. 2004;126:12760-12761.

20. Cheng YY, Wang JR, Rao TL, He XX, Xu TW. Pharmaceutical applications of dendrimers: promising nanocarriers for drug delivery. Front Biosci. 2008;13:1447-1471.

21. Hu JJ, Cheng YY, Ma YR, Wu QL, Xu TW. Host-guest chemistry and physico-chemical properties of dendrimer-mycophenolic acid complexes. J Phys Chem B. 2009;113:64-74.

22. Yang K, Cheng YY, Feng XY, Zhang JH, Wu QL, Xu TW. Insights into the interactions between dendrimers and multiple surfactants: 6 . Formation of miscellaneous mixed micelles revealed by a combination of 1H NMR, diffusion, and NOE analysis. $J$ Phys Chem B. 2010;114: $7265-7273$.

23. Yang K, Weng L, Cheng YY, et al. Host-guest chemistry of dendrimer-drug complexes. 6. fully acetylated dendrimers as biocompatible drug vehicles using dexamethasone 21-phosphate as a model drug. J Phys Chem B. 2011;115:2185-2195.

24. Cheng YY, Xu ZH, Ma ML, Xu TW. Dendrimers as drug carriers: applications in different routes of drug administration. J Pharm Sci. 2008;97:123-143

25. Yang WJ, Li YW, Cheng YY, Wu QL, Wen LP, Xu TW. Evaluation of phenylbutazone and poly(amidoamine) dendrimers interactions by a combination of solubility, 2D-NOESY NMR, and isothermal titration calorimetry studies. J Pharm Sci. 2009;98:1075-1085.

26. Liu JY, Pang Y, Huang W, Zhu XY, Zhou YF, Yan DY. Self-assembly of phospholipid- analogous hyperbranched polymers nanomicelles for drug delivery. Biomaterials. 2010;31:1334-1341.

27. D'Emanuele A, Attwood D. Dendrimer-drug interactions. Adv Drug Deliv Rev. 2005;57:2147-2162.

28. Kojima C, Toi Y, Harada A, Kono K. Preparation of poly(ethylene glycol)-attached dendrimers encapsulating photosensitizers for application to photodynamic therapy. Bioconjug Chem. 2007;18:663-670.
29. Vohs JK, Brege JJ, Raymond JE, Brown AE, Williams GL, Fahlman BD. Low-temperature growth of carbon nanotubes from the catalytic decomposition of carbon tetrachloride. J Am Chem Soc. 2004;126:9936-9937.

30. Cheng YY, Li YW, Wu QL, Zhang JH, Xu TW. Generation-dependent encapsulation/electrostatic attachment of phenobarbital molecules by poly(amidoamine) dendrimers: evidence from 2D-NOESY investigations. Eur J Med Chem. 2009;44:2219-2223.

31. Zhao LB, Cheng YY, Hu JJ, Wu QL, Xu TW. Host-guest chemistry of dendrimer-drug complexes. 3. Competitive binding of multiple drugs by a single dendrimer for combination therapy. J Phys Chem B. 2009;113:14172-14179.

32. Medina SH, EI-Sayed ME. Dendrimers as carriers for delivery of chemotherapeutic agents. Chem Rev. 2009;109:3141-3157.

33. Cheng YY, Zhao LB, Li YW, Xu TW. Design of biocompatible dendrimers for cancer diagnosis and therapy: current status and future perspectives. Chem Soc Rev. 2011;40:2673-2703.

34. Duncan R, Izzo L. Dendrimer biocompatibility and toxicity. Adv Drug Deliv Rev. 2005;57:2215-2237.

35. Kuo JS, Jan MS, Lin Y. Interactions between U-937 human macrophages and poly(propyleneimine) dendrimers. J Control Release. 2007;120:51-59.

36. Thomas TP, Majoros IJ, Kotlyar A, Mullen D, Banaszak Holl MM, Baker Jr JR. Cationic poly(amidoamine) dendrimer induces lysosomal apoptotic pathway at therapeutically relevant concentrations. Biomacromolecules. 2009;10:3207-3214.

37. Waite CL, Sparks SM, Uhrich KE, Roth CM. Acetylation of PAMAM dendrimers for cellular delivery of siRNA. BMC Biotechnol. 2009;9:38.

38. Jain K, Kesharwani P, Gupta U, Jain NK. Dendrimer toxicity: Let's meet the challenge. Int J Pharm. 2010;394:122-142.

39. Kolhatkar RB, Kitchens KM, Swaan PW, Ghandehari H. Surface acetylation of polyamidoamine (PAMAM) dendrimers decreases cytotoxicity while maintaining membrane permeability. Bioconjug Chem. 2007;18:2054-2060.
International Journal of Nanomedicine

\section{Publish your work in this journal}

The International Journal of Nanomedicine is an international, peerreviewed journal focusing on the application of nanotechnology in diagnostics, therapeutics, and drug delivery systems throughout the biomedical field. This journal is indexed on PubMed Central, MedLine, CAS, SciSearch ${ }^{\circledR}$, Current Contents ${ }^{\circledR} /$ Clinical Medicine,

\section{Dovepress}

Journal Citation Reports/Science Edition, EMBase, Scopus and the Elsevier Bibliographic databases. The manuscript management system is completely online and includes a very quick and fair peer-review system, which is all easy to use. Visit http://www.dovepress.com/ testimonials.php to read real quotes from published authors. 